\title{
A study of human gall bladder muscle in vitro
}

\author{
A. J. MACK AND J. K. TODD \\ From the Department of Surgery, The Victoria Infirmary, Glasgow
}

There is no technique which gives direct information on the contraction of the human gall bladder in vivo. Methods which have been used, depending on radiology (Burton, Harper, Howat, Scott, and Varley, 1960), or on the aspiration of bile by duodenal intubation, show the gall bladder emptying, but emptying does not necessarily imply contraction of the gall bladder wall, since it also depends on the activity of the sphincter of Oddi and surrounding duodenal musculature. Thus the action of drugs on the bile duct sphincter mechanisms may well mask any action which they have on the muscle of the gall bladder itself. A calculus impacted in the neck of the gall bladder, with consequent obstruction of the cystic duct, is a common cause of biliary pain. It is usual to treat this pain with pethidine and atropine, although as has been indicated, we have no direct knowledge of the action of these drugs on the gall bladder muscle or even of the basic physiology of the tissue. The in vitro technique seems to be applicable to the investigation of this problem.

The present study was undertaken in order to investigate the physiology and pharmacology of smooth muscle of the gall bladder. No such study appears to have been made previously, as the existing accounts have been derived from the indirect experimental techniques referred to above and by extrapolation from results obtained on lower animals. In vitro studies of isolated gall bladders or of strips of gall bladder wall have been mainly concerned with the dog and guinea pig which are technically suited to this method. Ravdin and Morrison (1931) did, however, study strips taken from the gall bladder of the Rhesus monkey. These authors also mention a single human gall bladder which contained multiple stones and whose wall was thickened by inflammatory change. Strips from the wall of this organ showed tone and spontaneous activity in an organ bath, but the authors did not examine the effect of added substances.

\section{METHODS}

Fifty strip preparations of human gall bladder from 25 specimens removed at operation were studied. Immediately after removal the unopened gall bladder was placed in Ringer lactate solution chilled to $4^{\circ} \mathrm{C}$ and gassed with $95 \% \mathrm{O}_{2}$ and $5 \% \mathrm{CO}_{2}$. Strips of the wall of the organ, containing muscle and mucosa, and about $20 \mathrm{~mm}$ by $2 \mathrm{~mm}$, were cut within two hours of removal. In the majority of experiments a pair of strips were set up together in the same organ bath giving a simultaneous record of the circular and longitudinal muscle.

The preparation was suspended in modified Krebs solution at $37^{\circ} \mathrm{C}$ equilibrated with the $95 \% \mathrm{O}_{2}$ and $5 \% \mathrm{CO}_{2}$ mixture. Recordings were made on a smoked drum using an isotonic system with a load of IG. A vibrator was used to reduce friction.

The modified Krebs solution was made up as follows (g/litre): $\mathrm{NaCl} 7 \cdot 8, \mathrm{KCl} \mathrm{0.35,} \mathrm{NaHCO}_{3} 1 \cdot 37, \mathrm{NaH}_{2} \mathrm{PO}_{4}$ $0 \cdot 165, \mathrm{CaCl}_{2} \mathbf{0} \cdot 28, \mathrm{MgCl}_{2} \mathbf{0} \cdot 01$, dextrose 1.4 .

The effect of the following pharmacologically active substances on the gall-bladder preparations was studied: acetylcholine chloride, physostigmine sulphate, atropine sulphate, histamine acid phosphate, mepyramine maleate, 5-hydroxytryptamine creatinine sulphate, isoprenaline sulphate, adrenaline hydrochloride, noradrenaline bitartrate, glyceryl trinitrate, sodium nitrite, nicotine acid tartrate, gastrin (pentapeptide ICI), secretin, and pancreozymin (Boots).

Gall bladders in which the wall was obviously diseased were discarded. Strips of the wall parallel to those used in the preparations were examined histologically.

\section{RESULTS}

SPONTANEOUS ACTIVITY Human gall bladder muscle strips show rhythmic spontaneous contraction and relaxation. Sustained tone is also shown. Slow but considerable changes in tone may also occur, as for example, during the period of 30 minutes after the preparation has been set up when a gradual rise in tone is often seen (Fig. 1). In any preparation there is a general correspondence between the degree of spontaneous activity, the sensitivity to added drugs, and the absence of fibrosis. In general, circular muscle strips are more active and more sensitive than are longitudinal.

CHOLINERGIC DRUGS Acetylcholine causes contraction of human gall bladder muscle strips (Fig. 2A), and the threshold for this effect is sometimes as low as $1 \mathrm{~m} \mu \mathrm{g} / \mathrm{ml}$. The contraction is powerful, reaching its maximum development in three minutes; 


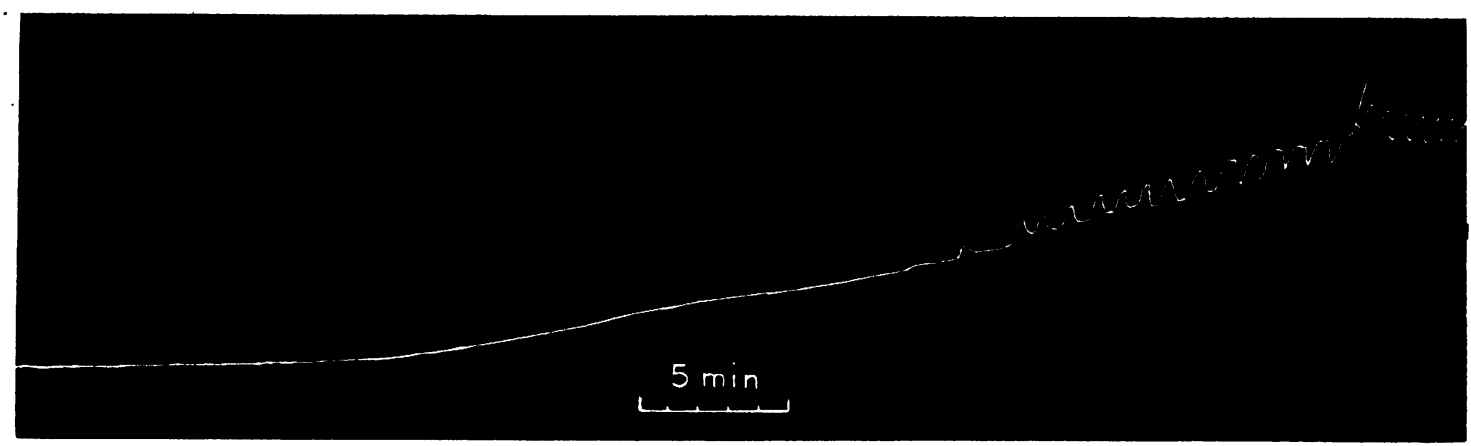

FIG. 1. A preparation of human gall bladder smooth muscle which exhibits a rising level of tone immediately after being set up followed by the onset of spontaneous activity.

the effect is sustained, gradually falling off over about 10 minutes unless the acetylcholine is removed by repeated changes of fresh Krebs solution. This action is potentiated by eserine and is abolished by atropine.

HISTAMINE Histamine in concentrations of $1 \mu \mathrm{g} / \mathrm{ml}$ causes a contraction similar to that seen with acetylcholine (Fig. 2B). This response is not affected by atropine but is abolished by mepyramine maleate.

5-HYDROXYTRYPTAMINE This substance in concentrations from $1 \mu \mathrm{g} / \mathrm{ml}$ to $100 \mu \mathrm{g} / \mathrm{ml}$ is without effect on the preparation.

BARIUM CHLORIDE A gradual rise in tone with increase in the amplitude of spontaneous contraction

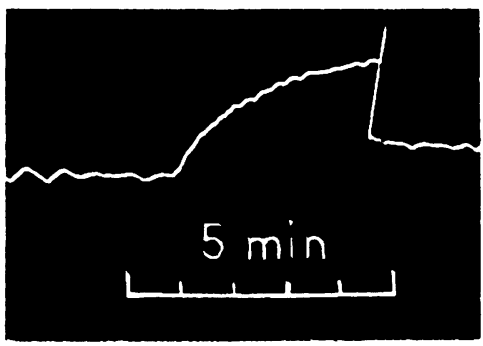

A

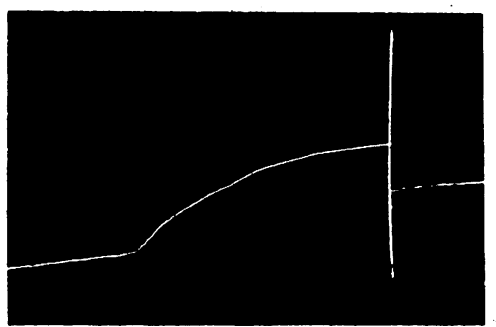

B

FIG. 2. The response of the smooth muscle of the human gall bladder to $(A)$ acetylcholine, $1 \mu \mathrm{g} / \mathrm{ml}$, and $(B)$ histamine, $1 \mu \mathrm{g} / \mathrm{ml}$. follows the addition of barium chloride to the bath to give a concentration of $100 \mu \mathrm{g} / \mathrm{ml}$. This effect takes five minutes to develop and is sustained.

MORPHINE Morphine sulphate has no action on the preparation in doses from $10 \mu \mathrm{g} / \mathrm{ml} \mathrm{up} \mathrm{to} 100 \mu \mathrm{g} / \mathrm{ml}$.

NICOTINE No significant effect is seen when nicotine is added to the bath to produce concentrations up to $100 \mu \mathrm{g} / \mathrm{ml}$.

CATECHOL AMINES The effects of isoprenaline, adrenaline, and noradrenaline were investigated. These substances have no effect on the preparation in the usual physiological dosage. In very high dosage $(100 \mu \mathrm{g} / \mathrm{ml})$ adrenaline has a weak motor action in a few cases. The catechol amines even in high dosage $(100 \mu \mathrm{g} / \mathrm{ml})$ do not reduce the contractile response to acetylcholine.

NITRATES AND NITRITES Glycerol trinitrate or sodium nitrite in dosage from $1 \mu \mathrm{g} / \mathrm{ml}$ to $1 \mathrm{mg} / \mathrm{ml}$ have no effect on the preparation. No inhibition of sustained tone is seen and no reduction in the contractile response to acetylcholine.

GASTROINTESTINAL HORMONES The synthetic gastrin preparation (Pentapeptide ICI) does not produce a contractile response in a dose range from $0.1 \mu \mathrm{g} / \mathrm{ml}$ to $1.0 \mu \mathrm{g} / \mathrm{ml}$ (Fig. 3A). The higher concentration seems to be associated with some reduction in the amplitude of spontaneous contraction and a reduction in the contractile response to acetylocholine given later. Secretin $(0.1 \mathrm{unit} / \mathrm{ml})$ has a slight but definite contractile action (Fig. 3B), while pancreozymin (0.025-0.5 units $/ \mathrm{ml})$ has a more powerful contractile action (Figs. 3C and 3D). Even when given in the maximum concentration, pancreozymin produces a slower response than acetylcholine, taking some five to 10 minutes to become fully 


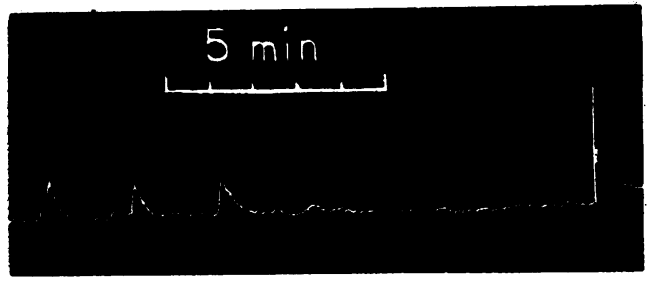

A
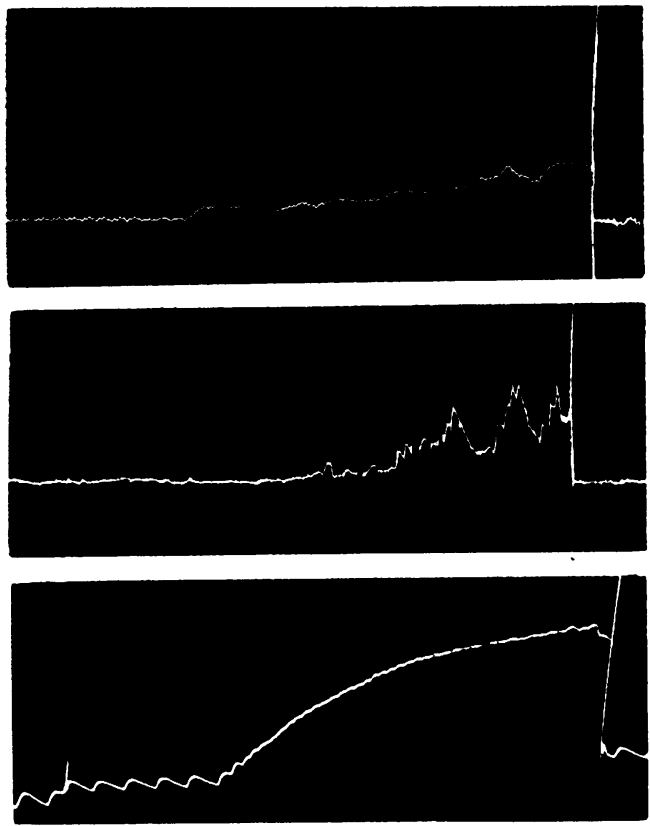

D

FIG. 3. The response of the smooth muscle of the human gall bladder to $(A)$ gastrin, $0 \cdot 1 \mu \mathrm{g} / \mathrm{ml},(B)$ secretin, $0 \cdot 1$ units $/ \mathrm{ml},(C)$ pancreozymin, 0.1 units $/ \mathrm{ml}$, and $(D)$ pancreozymin, 0.5 units $/ \mathrm{ml}$.

developed, but the amplitude of the response corresponds with the maximal response to acetylcholine. The action of pancreozymin is not affected by atropine or hexamethonium.

\section{DISCUSSION}

The gall bladder acts as a reservoir for bile and plays a part in the regulation of biliary pressure. There has been argument in the past as to whether the muscle tissue in the wall plays an active role in the expulsion of stored bile or simply aids in preventing distension and in adjusting to variations in the volume of the contents as suggested by Halpert and Lewis (1930).

The present findings that the human gall bladder muscle is capable of showing maintained tone in vitro and of contracting powerfully in response to certain substances, in particular to acetylcholine and cholecystokinin, demonstrates that the gall bladder does contract and contraction plays a part in evacuating its contents. Not unexpectedly the capacity to show tone and spontaneous activity are lost in proportion to the degree of fibrous replacement of muscle fibres.

The response of human gall bladder muscle to acetylcholine is similar in most respects to that of intestinal smooth muscle. Thus the threshold concentration for contraction was sometimes as low as $1 \mathrm{~m} \mu \mathrm{g} / \mathrm{ml}$ and the effect was potentiated by eserine and blocked by atropine. On the other hand, the time course of the contraction was slower than that shown by intestinal muscle. The time taken for the development of the maximal contractile response varied between three and five minutes. Maximum contraction in colonic muscle strips is usually developed in less than 30 seconds. This difference was less marked with those gall bladder strips in which the histology was closest to normal. On most occasions the routine premedication given to the patients included atropine $0.6 \mathrm{mg}$ but in spite of this the muscle retained its sensitivity to acetylcholine. This accords with the findings of Fishlock and Parks (1963) in human colonic muscle. It also suggests that the common practice of giving atropine $0.6 \mathrm{mg}$ to patients with biliary colic is unlikely to have much effect on the gall bladder.

In the present investigation there was a striking absence of response to the adrenergic monoaminesnoradrenaline, adrenaline, and isoprenaline-even in concentrations as high as $100 \mu \mathrm{g} / \mathrm{ml}$. There is some confusion in the older work on in vitro studies on animal tissue regarding the action of adrenaline (Ivy, 1934). Motor, inhibitory, biphasic, and negative results have all been described. These results taken together suggest that the cholinergic innervation of the gall bladder is more important than the adrenergic, but it is difficult to assess the importance of the role played by the innervation in the maintenance of normal function, and Rudick and Hutchison (1964) found that the volume of the human gall bladder, judged on the basis of cholecystography, was doubled after total abdominal vagotomy and that its emptying was somewhat impaired, suggesting that the vagus nerve normally exerts a tonic influence on the viscus.

The rapid contractile response to histamine and the slow rise in tone seen in the presence of barium chloride are both similar to the responses of other alimentary smooth muscle and agree with the findings of animal experiments.

The nitrites are usually said to relax biliary muscle including that of the gall bladder (Goodman and Gilman, 1965). Certainly there is evidence for a relaxant effect on the sphincter of Oddi, since Myers, 
Haupt, Birkhead, and Deaver (1962) demonstrated a fall in common duct pressure by means of T-tube manometry in post-cholecystectomy patients following the inhalation of amyl nitrite. We, on the other hand, were unable to demonstrate any effect of sodium nitrite or glyceryl trinitrate on gall bladder muscle in concentrations as high as $100 \mu \mathrm{g}$, and in particular acetylcholine in concentrations of $1 \mu \mathrm{g} / \mathrm{ml}$ still produced a powerful contraction in the presence of these high concentrations of sodium nitrite.

Another much discussed question is the action of morphine on the biliary apparatus. Goodman and Gilman state that the injection of $10 \mathrm{mg}$ morphine is followed by a marked rise in intrabiliary (common duct) pressure and that this is often accompanied by a sensation of epigastric discomfort or even typical biliary colic. Most animal experiments using the in vitro technique have shown little or no action (Macht, 1917; Lieb and McWhorter, 1915). In the present study we were unable to show any direct pharmacological action of morphine on gall bladder muscle in vitro.

The actions of the various gastrointestinal hormone preparations is of interest since it is some such mechanism which plays the main part in regulating the expulsion of bile after a meal. The presence of a gastrointestinal hormone which could cause gall bladder contractions was first demonstrated in vivo and by cross circulation experiments by Ivy and Oldberg (1928) and it was they who first suggested the name cholecystokinin. Halpert and Lewis (1930) found it was without effect on an in vitro preparation of dog tissue. The discrepancy was resolved by Jung and Greengard (1933) who showed that the usual motor effect could be demonstrated in vitro using guinea pig tissue but that a concentration approximately 50 times that needed in vivo was required. They attributed the difference to the large size of the cholecystokinin molecule relative to acetylcholine and to the slower diffusion from the bathing fluid in an organ bath compared with diffusion from the blood stream. Our findings are in keeping with this concept. Up to 50 units (half the total adult dose) of pancreozymin (which contains cholecystokinin) must be added to a $200 \mathrm{ml}$ organ bath in order to obtain a maximal contractile effect. Burton et al (1960) have described the response to secretin and cholecystokinin given intravenously and have evolved this into a semiquantitative test of gall bladder contractile function. They found by means of radiology that the emptying action of cholecystokinin was maximal at 12 minutes and corresponded to a reduction in volume of $\mathbf{4 0}$ to
$50 \%$ of the resting volume. This time course is similar to that shown by our preparation in vitro.

The most significant conclusions to be drawn from the foregoing discussion are that the main pharmacological properties of human gall bladder muscle which serve to distinguish it from smooth muscle elsewhere in the alimentary canal are its lack of response to adrenergic substances and to nitrites and its sensitivity to cholecystokinin.

\section{SUMMARY}

A study of the pharmacology of the smooth muscle of the human gall bladder is reported. Smooth muscle of the gall bladder responds to acetylcholine and histamine in a similar fashion to intestinal smooth muscle, but is unresponsive to adrenergic substances.

Morphine, the nitrite drugs, 5-hydroxytryptamine, and nicotine are without effect.

Cholecystokinin possesses a powerful contractile action, whereas the synthetic peptide gastrin does not.

We wish to thank the surgeons of the Department of Surgery, the Victoria Infirmary, Glasgow, for supplying the specimens; Roche Products Limited for supplying the acetylcholine chloride; and $\mathrm{Mr} \mathbf{R}$. Callander of the Department of Physiology, the University, Glasgow, for help with the illustrations.

\section{REFERENCES}

Burton, P., Harper, A. A., Howat, H. T., Scott, J. E., and Varley, H. (1960). The use of cholecystokinin to test gall bladder function in man. Gut, 1, 193-204.

Fishlock, D. J., and Parks, A. G. (1963). A study of human colonic muscle in vitro. Brit. med. J., 2, 666-667.

Goodman, L. S., and Gilman, A. (1965). The Pharmacological Basis of Therapeutics, 3rd ed. Macmillan, New York.

Halpert, B., and Lewis, J. H. (1930). Experiments on the isolated whole gall-bladder of the dog. Amer. J. Physiol., 93, 506-520.

Ivy, A. C. (1934). The physiology of the gall bladder. Physiol. Rev., 14, 1-102.

contraction and evacuation. Amer. J. Physiol., 86, 599-613.

Jung, F. T., and Greengard, H. (1933). Response of the isolated gall bladder to cholecystokinin. Amer.J. Physiol., 103, 275-278.

Lieb, C. C., and McWhorter, J. E. (1915). Action of drugs on the isolated gall-bladder. J. Pharmacol. exp. Ther., 7, 83-98.

Macht, D. I. (1917). On the comparative effects of the opium alkaloids individually and in combination with each other on the gallbladder. Ibid., 473-481.

Myers, R. N., Haupt, G. J., Birkhead, N. C., and Deaver, J. M. (1962). Cinefluorographic observations of common bile duct physiology. Ann. Surg., 156, 442-450.

Ravdin, I. S., and Morrison, J. L. (1931). Gall bladder function. I. The contractile function of the gallbladder. Arch. Surg., 22, 810-828.

Rudick, J., and Hutchison, J. S. F. (1964). Effects of vagal-nerve section on the biliary system. Lancet, $1,579-581$. 